\title{
El debate sobre Plato und die Dichter y su inscripción en el contexto de Alemania \\ Nacional-Socialista: una discusión con lecturas de la teoría política
}

\section{The debate on Plato und die Dichter and its inscription in the context of National Socialist Germany. A discussion with the political theory interpretations}

\section{Dndo. Facundo Norberto Bey facundo.bey@gmail.com Universidad Nacional de General San Martín, Argentina}

( Hans-Georg Gadamer, en su conferencia Plato und die Dichter (1934), desarrolló una investigación fenomenológica excepcional de filosofía éticopolítica de Platón y del lugar que el arte ocupa en ella. En mediados de la década de 1990, la escritora mexicana Teresa Orozco publicó una serie de escritos en los cuales acusa a Gadamer de haberse colocado, a través de la exhibición y publicación de este trabajo, a servicio del nacional-socialismo. Este artículo busca discutir los argumentos presentados por Orozco y otros autores, en primer lugar, investigando la heterogeneidad de la recepción del texto en cuestión entre 1934 y 1944, dentro y fuera de Alemania; en segundo lugar, recuperando datos biográficos relevantes que fueron omitidos por sus detractores; $y$, finalmente, ofreciendo pruebas documentales que refuten los fundamentos de la acusación mencionada anteriormente. Al final, haré una propuesta de lectura metodológica para analizar el trabajo de referencia en relación a su contexto histórico, lo que puede contribuir para verificar en qué sentido esta conferencia expresaría la disidencia de Gadamer con la hegemonía Nacional-Socialista

PALABRAS-CLAVE

Gadamer. Hermenéutica filosófica. Platón.

Política. Nacional-Socialismo. Arte. História 
Hans-Georg Gadamer, in his conference Plato und die Dichter [1934], executed an exceptional phenomenological investigation of the Plato's ethical-political philosophy and of the place of art in it. In the mid-1990s, the Mexican author Teresa Orozco published a series of works in which she accused Gadamer of placing himself, through the presentation and publication of Plato und die Dichter, at the service of National Socialism. This article seeks to discuss Orozco's and others arguments, in the first place, inquiring about the heterogeneity of its reception between 1934 and 1944, inside and outside of Germany; then, regaining relevant biographical information omitted by their detractors; finally, offering documentary evidence that would refute the grounds of the aforementioned accusation. Lastly, I will propose a methodological framework to analyze Plato und die Dichter in relation with its historical context. It could show in what sense Plato und die Dichter may have expressed Gadamer's dissidence with the National Socialist hegemony.

\section{KEYWORDS Gadamer. Philosophical Hermeneutics. Plato. Politics. National Socialism. Art. History}


El debate sobre Plato und die Dichtery su inscripción en el contexto de Alemania Nacional-Socialista: una discusión con lecturas de la teoría política

Uno asume que lo que fue publicado en 1934 tuvo que haber sido escrito en 1934. Pero nosotros no somos periodistas. A menudo escribimos años por anticipado y lo que eventualmente será publicado no refleja del todo la situación histórica y política del año de publicación Hans-Georg Gadamer $(1997,256)^{1}$.

Y para mi está claro que es mera hipocresía preguntar: ¿por qué no se rebeló contra eso? Cuando se le enfrentan con armas, uno no las contrarresta con la predicación

Hans-Georg Gadamer (Derrida, Gadamer, Lacoue-Labarthe, 2014, 52-53).

Plato und die Dichter [Platón y los poetas] fue pronunciada como conferencia por Hans-Georg Gadamer el 24 de enero de 1934 en la Gesellschaft der Freunde des humanistischen Gymnasiums por invitación de su presidente, el teólogo Rudolf Bultmann, asociación que se reunía en el Gymnasium Philippinum de Marburgo. En 1933 Gadamer había presentado a Vittorio Klostermann, editor de su amigo Max Kommerell, un manuscrito de cien páginas, que fuera luego examinado por Karl Reinhardt y Walter F. Otto. Se trataba de la primera versión de la conferencia. A pesar del beneplácito de Reinhardt, Klostermann se vio en la necesidad de devolverle a Gadamer su trabajo para realizar modificaciones debido al rechazo que encontró en el dictamen de Otto. Esta experiencia frustrante lo convenció de reestructurar el texto y hacer de él una nueva versión más corta (su extensión se redujo a menos de la mitad), a la que luego le introdujo la siguiente frase de Johann W. v. Goethe a modo de epígrafe ${ }^{2}$ :

Por todo escrito filosófico cruza, aunque llegase a ser muy poco visible, un cierto hilo polémico. Quien filosofa no está de acuerdo con las ideas de su tiem-

1 Todas las traducciones de este texto me pertenecen, así como las relativas al volumen 5 de la Gesammelte Werke (GW) y otros textos y entrevistas de Gadamer citados en el presente artículo, salvo cuando se haga estricta referencia a ediciones en castellano.

2 Se trata de la breve reseña crítica de Goethe de 1796, titulada Plato als Mitgenosse einer christlicher Offenbarung [Platón como partícipe de una revelación cristiana], sobre la traducción del Ion por parte del poeta Friedrich Leopold de Stolberg-Stolberg, texto que, bajo su paródico título prodigó a Gadamer las palabras del epígrafe. En ese ensayo crítico, Goethe banalizaba la lectura literal del Conde Leopold, incapaz desde su perspectiva de comprender la vindicación retórica de lo sagrado del poeta Ion como un gesto irónico de Sócrates digno de un escenario aristofánico, dirigido contra la pretensión de mistificación del arte. 
po presente ni pasado, y por eso los diálogos de Platón están no sólo dirigidos $a$ algo sino también contra algo (GW 5, 187).

La conferencia fue finalmente publicada en 1934 y reimpresa sin modificaciones en el quinto tomo de su Gesammelte Werke. Su particularidad se encuentra en que se trata de uno de los pocos textos de Gadamer en el que desarrolla una investigación fenomenológica de la filosofía ético-política de Platón y del lugar que el arte ocupa en ella ${ }^{3}$, publicado en un contexto político y cultural que es difícil soslayar: la caída de la República de Weimar y el ascenso del nacionalsocialismo.

\section{Teresa Orozco: el arte de la violencia interpretativa}

A mediados de la década de 1990 la autora mexicana Teresa Orozco publicó su tesis doctoral por la Freies Universität Berlin, que llevaba por título Platonische Gewalt. Gadamers politische Hermeneutik der NS-Zeit (1995a) [Violencia platónica. La política hermenéutica de Gadamer durante el Nacionalsocialismo]. Ese mismo año publicó también un artículo titulado Die Kunst der Anspielung. Hans-Georg Gadamers philosophische Interventionen im NS (1995b) [El arte de la insinuación. Las intervenciones filosóficas de Hans-Georg Gadamer en el nacionalsocialismo]. El eje "argumentativo" del libro, que le reserva un lugar privilegiado a Plato und die Dichter, se encuentra sintetizado en el artículo y conviene, por tanto, reponerlo con sus propias palabras:

La construcción completa de la interpretación de Gadamer, tal como se muestra en una lectura más detallada, presenta un horizonte hermenéutico que es congruente con la autocomprensión ideal del nacionalsocialismo como "decisión política" para la "renovación del Estado" tras la ruina de la República de Weimar: así sería comprensible la expulsión de los poetas como decisión y medida política para la nueva fundación del Estado (2004a, 79).

El artículo de Orozco buscaba convencer al lector, por medio de una combinación superficial de declaraciones y recortes antojadizos del texto gadameriano, de que el marburgués, mediante sus ambiguas intervenciones teóricas,

3 Para un análisis más pormenorizado de esta conferencia de Gadamer cfr. Autor (2017; en prensa). 

lecturas de la teoría política

se habría puesto al servicio del nacionalsocialismo y lo habría hecho, además, con cierta simpatía, al menos en sus inicios. Los problemas del texto de Orozco son infranqueables. Justifica sus lecturas en alocuciones y textos de otros autores, la mayoría de ellos nazis consagrados (incluso criminales de guerra). No analiza las fuentes primarias en lo más mínimo, ni los diálogos platónicos y, en consecuencia, desatiende los argumentos de ambos registros. Mucho menos se interesa por distinguir la heterogeneidad de enfoques que buscaban instrumentalizar políticamente la filosofía platónica vigentes en esos años. Deliberadamente ignora las puntualísimas críticas de Gadamer, de connotación evidentemente política, a las lecturas clasicistas de Ulrich Wilamowitz-Moellendorff y del Dritte Humanismus [Tercer humanismo] de Werner Jaeger. Sólo animada por el interés de la mera polémica, imputa a motivos psicológicos y sociológicos decisiones interpretativas de Gadamer, hasta las más insignificantes. Entre otras cosas, llega al límite de recriminar a Gadamer el no haber criticado en forma manifiesta y directa al nacionalsocialismo en su texto de 1934, lo que obviamente hubiera implicado para el marburgués la separación de la Universidad, el confinamiento y, eventualmente, la muerte. Según cuenta Richard E. Palmer, Gadamer "no respondió al libro de Orozco, me dijo en 1996, porque no le daría una publicidad que no merecía. Simplemente lo ignoró. Dijo que este tema ya había sido discutido abiertamente en varias entrevistas que eran parte del registro público" (2002a, 228)

Toda la argumentación de Orozco se basaba en una idea que desafía el esfuerzo de la autora hasta sus fundamentos: "el texto de la conferencia está atravesado por una compleja red de resonancias interdiscursivas a las que el lector actual no tiene acceso" (2004a, 80). Como sucedáneo del "concepto de contexto" la autora presentó en su trabajo lo que entendió como un instrumento portador de un "mayor grado de precisión": el de "relaciones de resonancia" (73)5. Los momentos más determinantes del texto donde pone en juego esta idea son dos: en primer lugar, en la buena recepción que habría tenido Plato und die Dichter entre las glosas publicadas en 1934 como protocolos de la revista Das Humanistische Gymnasium, "relacionadas con las connotaciones elaboradas por Gadamer" (80). De ellas, destaca la autora la única comunicación enviada a la revista dedicada a reseñar la conferencia de Gadamer. Orozco extrae de ella una serie de frases aisladas, que se encuentran sobre el final del texto original, a las que busca identificar con la retórica oficialista, intentando demostrar de este

4 La traducción me pertenece.

5 El acceso privilegiado de Orozco se debe, según justifica, a su recurso a la armazón teórica del análisis interdiscursivo según el modelo del teórico althusseriano Michel Pêcheux. 

lecturas de la teoría política

modo la indiscutible afinidad de la textualidad gadameriana con la del presunto fascismo personificado esa tarde de enero de 1934, del cual este lector inidentificado por la autora habría formado parte $(80)^{6}$. Si se analiza este escueto informe de tan sólo una página, elaborado por un académico de apellido Westerburg, es posible encontrar un sumario resumen de algunos argumentos generales de la conferencia que se cierra con una frase que efectivamente podría ser interpretada como una apropiación cercana a la jerga fascista, a pesar del poco vehemente tono descriptivo general del texto: "La poesía mítica de Platón, así como su poesía dialógica, muestran una verdadera capacidad poética, que se pone al servicio de la nueva imagen del hombre"7 $(1934,100)$. Por lo demás, el informe menciona un eje argumental central por el cual Gadamer se distinguió en esos años, al reconocer la naturaleza utópica de República, de las apropiaciones programáticas de República, abiertamente partidarias y favorables al nacionalsocialismo, tal como la de Kurt Hildebrandt (1933a; 1933b; 1935), y que Orozco deliberadamente omite. Westerburg lo resume así: "Su Estado no es un Estado en la Tierra, sino la imagen originaria [Urbild] en el cielo" (100), aludiendo a los pasajes en los que en Plato und die Dichter Gadamer afirma que República había sido en la filosofía platónica un "Estado en palabras" (GW 5, 196), un

"[...] Estado en el pensamiento, no un Estado en la Tierra. Es decir, su propósito es iluminar algo y no proveer un plan de acción para un orden mejorado en la vida política real. El Estado de Platón es una imagen originaria en los cielos para cualquiera que desee ordenarse a sí mismo y a su constitución interna. [...] Quien se reconoce a sí mismo en ello no lo hace, sin embargo, como [un ente] aislado sin Estado. Reconoce en sí mismo el fundamento sobre el cual la realidad del Estado está construida a pesar de cuán degenerado y deformado pueda encontrarse el Estado real en el que vive (GW 5, 194).

En la medida en que esta idea había sido ya anticipada en 1931 en el primer libro del autor, Platos dialektische Ethik. Phänomenologische Interpretationen zum Philebos [La ética dialéctica de Platón. Interpretaciones fenomenológicas del Filebo], reelaboración de su tesis de habilitación presentada en 1928, aquí

6 Orozco refiere únicamente que se encuentra en la página 100 del número de 1934 de la revista.

7 La traducción me pertenece. 
El debate sobre Plato und die Dichtery su inscripción en el contexto de Alemania Nacional-Socialista: una discusión con lecturas de la teoría política

se pone de manifiesto que una de las "resonancias" que Orozco desatiende es la que tiene a Plato und die Dichter no como estímulo sino como consecuencia: la formación académica de Gadamer y todos sus estudios previos sobre filosofía antigua desde 1922 (sobre todo sobre ética) y los debates que en ellos se proyectan $^{8}$. En las primeras páginas del libro sobre el Filebo platónico puede leerse: "República no es un programa de reformas constitucionales entre otros, dirigido a tener un efecto político directo, sino, en cambio, un estado educacional [Staat der Erziehung]" (GW 5, 6). Quizás el "contexto" de la obra del propio autor no llegue a ser un "concepto" con las expectativas de precisión que buscó formular Orozco, pero tampoco es un guiñapo.

En segundo lugar, la autora recurre al informe favorable de la Universidad de Leipzig, con relación al requerimiento de Gadamer para ejercer la docencia (por lo tanto, circa 1938), que reza que Plato und die Dichter mostraría "una interpretación completamente original de la doctrina del Estado de Platón, que gana una nueva actualidad con la comprensión de que el lugar de soldados y guardianes es en el Estado platónico el lugar del hombre" (Orozco, 2004a, 82) ${ }^{10}$.

En los dos casos citados, como es evidente, la "resonancia" del texto se encontraba fuera del control de Gadamer y no podría imputársele legítimamente al autor la interpretación tergiversada de sus receptores o clasificarla con ligereza como compatible con el discurso nazi. Un absurdo tal nos obligaría a convocar al estrado también a Platón, por los mismos motivos. Si, como reconoció la autora, Platón fue utilizado por interpretaciones fascistas "en el ámbito lingüístico germánico”, ¿por qué la interpretación de Gadamer estaría menos expuesta a este riesgo? Esa reapropiación fascista de Gadamer, que no puede achacársele como una responsabilidad propia en el marco notoriamente represivo de un régimen dictatorial, podría haber existido entre sus lectores y evaluadores, tanto como en los años '90 existió en Orozco, sin que él ni nadie pudiera hacer algo al respecto para evitarlo.

8 Me refiero en particular a Der aristotelische Protreptikos und die entwicklungsgeschichtliche Betrachtung der aristotelischen Ethik [El Protréptico aristotélico desde el punto de vista del tratamiento del desarrollo histórico de la ética aristotélica] [1928], Praktisches Wissen [Saber práctico] [1930] y Platos dialektische Ethik. Phänomenologische Interpretationen zum Philebos [La ética dialéctica de Platón. Interpretaciones fenomenológicas del Filebo] [1931] y Die neue Plato-Forschung [La nueva investigación sobre Platón] [1933], todos contenidos en el Band 5 de la Gesammelte Werke (GW 5) e inéditos en castellano (a excepción del último). Cfr. también Autor (en prensa).

9 La expresión "erziehenden Staat" se encuentra presente en el emblemático primer volumen del libro de Paul Friedländer sobre Platón $(1964,127)$ [1928].

10 Según refiere Orozco el citado informe se encuentra en el Archivo de la Universidad de Leipzig, documento 41 (2004a, 82, n. 64). 
El debate sobre Plato und die Dichtery su inscripción en el contexto de Alemania Nacional-Socialista: una discusión con lecturas de la teoría política

Pero existen otras "resonancias interdiscursivas" que Orozco no ha tomado en consideración y que, si bien por los mismos motivos no pueden generar nada distinto que las precedentes, colaboran al menos en percibir la heterogeneidad de su recepción. Por lo menos cuatro reseñas se publicaron sobre el texto de Gadamer, la mayoría de ellas distantes de las presiones de la dictadura nazi o de cualquier simpatía por ella, pero, al mismo tiempo, muy cercanas en términos cronológicos. Más precisamente se trata de los trabajos críticos del renombrado especialista estadounidense en filosofía clásica Harold Cherniss (1936), del escocés Jonathan Tate (1936), del irlandés William Bedell Stanford (1937), y del prolífico filólogo clásico y filósofo alemán Kurt von Fritz (1936), quien fuera asistente del célebre teólogo Karl Barth, el único profesor universitario en Alemania que había rechazado en 1934 el juramento de servicio a Adolf Hitler $\mathrm{y}$, por ese motivo, puesto en retiro obligatorio ${ }^{11}$.

El entonces Profesor Asociado de la Johns Hopkins University, Harold Cherniss, que ya estaba familiarizado con los estudios de Gadamer sobre Aristóteles, no encontró particularmente novedoso el trabajo sobre Platón. A pesar de ello, abría su reseña diciendo que "si aún existen intérpretes que podrían emprender una «disculpa» al ataque de Platón a la poesía como una mera crítica de lo que él pudo haber percibido como arte degenerado en sus días, van a aprovechar esta conferencia"12 (1936, 229-230), sugiriendo desde el inicio que Plato und die Dichter se sitúa fuera de esa tendencia interpretativa. La reseña, muy breve, asiente por tradicionales algunas de las hipótesis del marburgués y sólo destaca “que al subrayar la importancia que Platón vio en el poder de la «imitación» para alterar el carácter del imitador, el Profesor Gadamer se acerca a decir algo que debería haber sido notado un largo tiempo atrás" (230).

Jonathan Tate, por su parte, ya en dos artículos previos a la reseña de Plato und die Dichter había buscado reconciliar y unificar el tratamiento platónico de la mímèsis en los libros III y X de República, atribuyéndole al ateniense la distinción entre sentidos buenos y malos o tipos de imitación (1928; 1932). Esta pers-

\footnotetext{
11 Von Fritz (1900-1985) se exilió primero en Oxford en 1936 — desde donde escribió la reseña- en el Corpus Christi College, y luego en los Estados Unidos, para volver a Alemania recién en 1954, donde enseño en la Freies Universität Berlin y en la Universität München. Von Fritz se encontraba indirectamente ligado a la organización de resistencia al nazismo Weiße Rose [Rosa blanca]: en 1931 se casó con Luise Eickemeyer, hermana del arquitecto Manfred Eickemeyer, quien les alquiló en el verano de 1942 a los miembros de la organización el departamento donde harían sus primeras reuniones. En 1943 Manfred Eickemeyer fue juzgado, pero finalmente logró ser absuelto por falta de pruebas. Como es sabido, la mayoría de los miembros tuvieron otro destino: los hermanos Hans y Sophie Scholl, Christoph Probst, Kurt Huber, Willi Graf y Alexander Schmorell fueron guillotinados y otras once personas fueron sentenciadas a prisión.
}

12 Las traducciones de los fragmentos citados de esta y las restantes reseñas me pertenecen. 

lecturas de la teoría política

pectiva se encuentra obrando de fondo en su recepción del trabajo de Gadamer, cuando afirma que éste debería tener más presente "[...] que la oposición de la filosofía a la poesía en Platón no aplica a la poesía qua poesía" pues "hay una variedad de «imitación» que Platón aprueba completamente. Es aquella practicada por los artistas y poetas que «hacen uso del paradigma divino» (Rep. 500d, etc.)" $(1936,147)$. Aunque el filólogo de la University of St. Andrews va a criticar a Gadamer por no admitir que "el tratamiento de Platón de la poesía es una deducción de su posición filosófica general, en particular, de la distinción entre conocimiento y opinión" (147), al final de la breve recensión dirá que "Entretanto, uno debe felicitarlo [a Gadamer] por [...] su tratamiento de los mitos platónicos en cuanto no [constituyen] mitos (en ningún sentido) ni poesía, y su comprensión de pasajes tales como Leyes 817 (las buenas leyes son genuina poesía)" (147).

Desde otra perspectiva, Stanford le asigna un lugar especial a la conferencia por poner en el centro de atención la prohibición platónica de toda poesía a excepción de los himnos a los dioses, héroes y ciudadanos virtuosos, un tema sensible para la tradición académica alemana, sobre todo para el romanticismo y clasicismo $(1937,233)$. Sin embargo, no sin ironía, destaca que la consideración de Gadamer sobre Platón como "una de las más grandes encarnaciones del genio poético de los griegos" (GW 5, 187) le da a la crítica hostil del ateniense un tono paradojal (Stanford, 1937, 234).

El punto específicamente político del análisis del catedrático del Trinity College se da en un pasaje en el que entiende que existe una temporalidad particular para el poeta y para el filósofo en la interpretación de Gadamer: "los poetas defienden el pasado, con todos sus encantadores vicios, su noble salvajismo. Platón miraba en dirección al futuro" (234). Inmediatamente da un paso en el que acusa a Gadamer, desde una postura que quizás quepa caracterizar como liberal, de permanecer callado, en el contexto de su conferencia, sobre la censura existente en Europa, refiriéndose seguramente no sólo al nacionalsocialismo alemán sino al fascismo italiano y al stalinismo (en la URSS fue el año de la llamada "Gran Purga"), movimientos políticos para entonces consolidados en el poder, cuyos proyectos se fundaban en la inauguración de una nueva era que barriera con la cultura precedente (liberal, burguesa o reaccionaria):

Homero tenía tan poco sitio en el Estado Ideal como lo tendría Tennyson en una Inglaterra Soviética. Uno no podría permitirle sobrevivir a los propagandistas (conscientes e inconscientes) de un ancient régime en el Estado Nuevo. El Sr. Gadamer no se ocupa de citar ningún 
ejemplo de censura política en la Europa contemporánea (Stanford, 1937, 234).

La crítica (mas no acusación) que formula Stanford a Gadamer, entonces, es la de proporcionar una lectura de Platón en la que se conjuga una visión para la fundación de un nuevo orden estatal y, en ese terreno, se alude a quienes ya no serían tolerados en él, sin que medie una palabra que impida una interpretación funcional al autoritarismo. Este llamado de atención a Gadamer se emplaza quizás en la incomprensión de Stanford de uno de los argumentos centrales del texto, esto es, la idea antes mencionada de que República es un "Estado en palabras" cuya finalidad no es la de "proveer un plan de acción para un orden mejorado en la vida política real" (GW 5, 196). Esta confusión no necesariamente implica sugerir que cabe retirar el reproche político que hace pesar Stanford sobre el marburgués, pero sí merece esclarecerse que tal amonestación no puede derivarse del fondo de su elaboración teórica.

Del mismo modo, Stanford parece no haber comprendido del todo la idea de "poesía dialógica" a la cual asimila con "la forma dialogada" platónica. Esta última, entendida desde su naturaleza formal, es considerada por el autor como simplemente más valiosa y útil para Platón, en términos prácticos, que los versos de los poetas tradicionales en el contexto de las pólis realmente existentes. Finalmente, Stanford cierra su reseña sin dureza (¿quizás con sarcasmo?): "Aunque el Sr. Gadamer tiene poco de nuevo para decir, reúne sus hechos y señalamientos convincentemente. Debe haber sido una conferencia excelente" (Stanford, 1997, 234).

El caso de von Fritz es, quizás, el más destacable. Por empezar, por ser no sólo un miembro de la academia alemana y un conocedor de sus discusiones más actuales sobre Platón, sino también por ser un exiliado político. A diferencia de los restantes autores que ofrecieron muy breves análisis del trabajo de Gadamer, von Fritz escribió desde Oxford cuatro meticulosas páginas que publicó nada menos que en Gnomon, revista dirigida por Werner Jaeger, quien en el mismo año de la publicación del texto se encontraba ya exiliado en los Estados Unidos, donde fue acogido por la Universidad de Chicago.

La reseña de von Fritz es la más lúcida y precisa de todas. Resume extraordinariamente bien los principales momentos del texto y las hipótesis de Gadamer, con una claridad que aún hoy debería proporcionarle un lugar destacado entre quienes se interesen por entender Plato und die Dichter. Von Fritz comienza celebrando el texto de Gadamer por considerar que su investigación sobre la 

lecturas de la teoría política

expulsión de los poetas en el Estado platónico, lejos de permanecer en el terreno de la explicación psicológica o histórica, se toma en serio sus propósitos aunando esfuerzos filológicos y filosóficos para "entender las cosas desde su raíz, sin imponerles de inmediato criterios que le son extraños, para ocuparse de ellas de manera libre e independiente" (1936, 251). Así, tras reconocer la orientación fenomenológica de Gadamer (y no la manipulación ideológica), von Fritz le da su atención antes que nada al carácter radical y novedoso que tendría la crítica platónica y que, según Gadamer, distancia al ateniense, en las exigencias de su querella a la poesía, de una tradición en la que se podrían mencionar los nombres de Jenófanes, Heráclito, Pitágoras y Anaxágoras (252). El punto crucial que destaca von Fritz es que, partiendo de la interpretación gadameriana de que la paideía platónica está orientada a despertar las fuerzas que forman el Estado, República está destinada a fundar aquello para lo cual la poesía tradicional resulta impotente, esto es, ese Estado en palabras que es de cada uno y en el que cada uno se considera parte de una unidad con los otros. En este sentido, señalará con agudeza, un Estado sano en cuanto orden humano sólo puede crecer como "un lento desarrollo desde dentro hacia afuera", donde "no tiene validez ninguna prohibición impuesta" ni hay lugar para que éste sea establecido por medio de una violencia exterior organizada (254). El trabajo de Gadamer es finalmente considerado por von Fritz

[...] una expresión de un genuino esfuerzo por no descartar las cosas con explicaciones bien definidas que buscan eliminar lo cuestionable y ocultar las profundas tensiones dentro de la cultura griega en favor de un hermoso humanismo colorido. En todas partes, intenta implacablemente penetrar en el corazón de la cuestión, ya que ésta por sí sola puede proporcionar la base para un examen fructífero de la antigüedad en el presente (255).

Por último, aunque no se trate de una reseña, cabe también mencionar la recepción que tuvo Plato und die Dichter, a diez años de su publicación, en un trabajo del filólogo neerlandés Willem Jacob Verdenius. En su Platon et la poesie [Platón y la poesía], Verdenius tomará el texto de Gadamer para hacer un comentario, que por su significatividad reproduzco aquí:

Esto significa que no debemos considerar a la República de Platón como un ideal que debemos esforzarnos por 
alcanzar, ni como un objetivo al que debe tender nuestra educación y organización política, sino como un espejo en el que podemos reconocer nuestro interior, como una piedra de toque para medir el propio conocimiento de uno mismo $(1944,131)^{13}$.

Como se puede apreciar, las "resonancias interdiscursivas" no pueden ser reducidas sólo a aquellas interpretaciones que se ponen al servicio de Orozco, para quien "[...] el texto está construido de tal modo que en el horizonte histórico de la comprensión del medio culto humanista se carga de significado fascista" (2004a, 80). Su recepción en su contexto histórico inmediato ha sido variada y con distinta suerte, tanto en términos teóricos como políticos. Esto no significa que la conferencia Plato und die Dichter no haya podido ser ocasionalmente apropiada ideológicamente por el discurso oficial de la dictadura nazi y sus instituciones educativas - aunque con una repercusión bastante restringida a las glosas aisladas de un círculo de estudios y a la evaluación interna de sus antecedentes para el puesto docente en Leipzig - , sino que no fue escrita ni pronunciada como resultado de un abyecto plan para congraciarse con la ideología oficial.

\section{Quandoque bonus dormitat Homerus!}

Orozco menciona también en su artículo que Gadamer se había asociado, sucesivamente, a la Nationalsozialistischer Lehrerbund [Liga Nacional de Profesores Nacionalsocialistas] (NSLB), a la organización de asistencia social Nationalsozialistische Volkswohlfahrt [Bienestar Popular Nacionalsocialista] (NSV) (cuyos beneficiarios eran obviamente sólo los niños, madres, empleados públicos, enfermos y ancianos considerados "arios" por el Estado) y a la organización deportiva Nationalsozialistischer Reichsbund für Leibesübungen [Liga Nacionalsocialista del Reich para el Ejercicio Físico] (DRL). Sin embargo, olvida decir que en ningún momento Gadamer se afilió al NSDAP, lo cual podría haberle costado la vida (Di Cesare, 2007, 27). Su caso era bien distinto del de alguien cuyo compromiso innegable le aseguraba protección a pesar de no pertenecer al Partido (como fue el caso de Hans Freyer).

La autora tampoco menciona que para 1935 el nombramiento de Gadamer como Profesor no se producía, como destacó Grondin, por

13 La traducción me pertenece. 

lecturas de la teoría política

[...] la oposición de la dirección del cuerpo docente [Dozentbund] [...]. Fue en nombre de esta organización que el entonces decano de la Facultad de Filosofía, el profesor [Friedrich] Wachtsmuth, escribió el 27 de abril de 1935 lo siguiente: "La dirección del cuerpo docente rechaza de momento el nombramiento del doctor Gadamer como catedrático supernumerario por una serie de razones que han sido dadas a conocer al decano por medio del abajo firmante, y al propio señor Gadamer por medio de la dirección. A ello hay que añadir que la habilitación del señor Gadamer sólo tuvo lugar el 23 de febrero de 1929, de modo que justo se han cumplido lo seis años reglamentarios" (2000, 241-242).

Los motivos por los que se rechazaba el nombramiento de Gadamer como catedrático se explicaban al margen del dictamen como sigue: "No se ha esforzado lo suficiente en integrarse en el cuerpo docente. Aún tiene que demostrar que posee un espíritu comunitario" $(2000,242)$. Ni Plato und die Dichter ni la falta de compromiso de Gadamer con los docentes nacionalsocialistas fueron en esta importante ocasión interpretados con complicidad y simpatía en "el horizonte histórico de la comprensión del medio culto humanista" cargado "de significado fascista" al que pertenecía el decano Wachtsmuth, historiador del arte y nacionalsocialista convencido. Fue entonces, continúa Grondin, que decidió inscribirse voluntariamente, como Gadamer reconoció en varias ocasiones, "en un campamento de rehabilitación político [Rehabilitierungslager] para docentes en Weichselmünde, cerca de Danzig" (2000, 242), entendiendo que sería la única manera de no renunciar a la carrera académica, de quizá algún día dejar de ser Privatdozent sin por ello comprometerse con el Partido ${ }^{14}$.

Pero lo que Orozco sobre todo no dice es algo que podría ser favorable a su propio argumento y que Geoffrey Waite fue el primero en mencionarlo en un artículo, aunque de un modo absolutamente desvirtuado (2004, 273). En realidad, el hecho fue documentado mucho antes por un autor conocido por Orozco, George Leaman, en el año 1993 (40-41). En su libro, Leaman publicó datos que recopiló en toda Alemania a partir de los archivos del NSDAP, el Amt Rosenberg, el Ministerio de Educación del Reich, el NS-Lehrerbund, las SS y la Gestapo. Lo que Leaman hace público en su libro Heidegger im Kontext Gesamtüberblick zum NS-Engagement der Universitätsphilosophen [Heidegger

14 Los agregados entre corchetes me pertenecen. Cfr. también Di Cesare (2007, 34-35). 

lecturas de la teoría política

en contexto. Imagen de conjunto del compromiso nacionalsocialista de los filósofos universitarios] como evidencia de la persecución ejercida por el régimen nazi, Waite lo reciclará como acusación. Una acusación que, paradójicamente, ya era tal, que se duplica. "Gadamer también — nos cuenta Waite — había sido un seguidor o adherente (Anhänger) del ultraderechista y racista Partido Nacional del Pueblo Alemán (DNVP)" ${ }^{15}(2004,273)$. El estadounidense deja a su lector en una atmósfera de estupor. El Deutschnationale Volkspartei había sido un partido sin dudas völkisch, con un discurso antisemita y Gadamer había sido su seguidor. Lo que no dice Waite también es digno de estupor, no menciona su fuente. $\mathrm{O}$ en realidad sí, afirma que su fuente es Leaman. Pero no dice quién es la fuente de Leaman...Friedrich Wachtsmuth, otra vez.

Existen unos pequeños detalles que este autor omitió junto con el del nombre del decano Wachtsmuth: en 1933 el DNVP se disolvió y fue absorbido por el NSDAP. Uno de sus líderes era Carl Friedrich Goerdeler, político conservador y monarquista, que desde 1931 comenzó a tomar distancia del partido justamente por el acercamiento que estaba practicando, de la mano del empresario antisemita Alfred Hugenberg, hacia el NSDAP y que, en 1933, fue decisivo para la llegada de Hitler no sólo al poder, sino al poder absoluto. Los miembros del DNVP que no aceptaron su disolución y el liderazgo absoluto de Hitler fueron hostigados y perseguidos. Goerdeler, sin embargo, no se alejó de la política $y$, aunque muchas veces desafiante, intentó ingenuamente y sin éxito domar al NSDAP y mantenerse independiente, sobre todo en sus puntos de vista sobre la política económica y las persecuciones a los judíos de la ciudad de Leipzig, de la que fue alcalde desde 1930 hasta 1937, fecha en la que renunció a su cargo. Por estos motivos fue visto por la dictadura nazi con una desconfianza cada vez mayor y fue paulatinamente aislado en términos políticos. En 1940 comenzó definitivamente a liderar en la clandestinidad un círculo conservador de la resistencia dispuesto a complotar contra el gobierno de Hitler. En 1945, Goerdeler, tal como había sucedido con su cómplice Claus von Stauffenberg, fue ejecutado por haber intentado el 20 de julio de 1944, por medio de un fallido atentado, asesinar a Hitler para inmediatamente, con complicidad de algunos oficiales de las fuerzas armadas, dar un golpe de Estado que estableciera un nuevo gobierno en Alemania, del cual sería su máxima autoridad. Gadamer, que seguramente no estaba al tanto del complot, reconoció años después a Goerdeler como uno de sus amigos durante ese mismo período $(2002,123)$. De hecho, en su autobiografía Gadamer comentó que, en una reunión en 1944 en casa del político, en

15 La traducción me pertenece. 
Leipzig, pronunció una conferencia sobre República, en medio de una atmósfera que, si bien no podría ser llamada de "complotismo" sí podría ser justamente llamada de oposición a una era insoportable que, después de la batalla de Stalingrado [1943], parecía en franca debacle (Gadamer, 1996, 140). Su relación con Goerdeler y su entorno debió haber sido estrecha, quizás intensificada por intermedio de su entonces asistente y futura esposa, Kate Lekebusch, íntima amiga de la hija de Goerdeler, Marianne, ambas alumnas de Gadamer, detenidas y condenadas por el Volksgerichtshof [Tribunal del Pueblo], que presidía el infame y sanguinario Juez Roland Freisler, a permanecer en diversos campos de concentración después del atentado. ${ }^{16}$

El tercer detalle que omitió Waite es la fecha y contenido de la denuncia de Wachtsmuth: 25 de diciembre de 1935. Habían pasado 8 meses de la negativa al nombramiento de Gadamer por motivos políticos y más de dos años desde la disolución del DNVP. Es evidente que a este punto ser tildado de seguidor del DNVP no significaba estricta adhesión a la propaganda antisemita del período de Hugenberg sino reprobación por los motivos por los cuales los que habían sido sus antiguos miembros no pasaron a engrosar las filas del NSDAP. Este es el texto original, presente en el Bundesarchiv-Dokumentationszentrale de Berlín: Gadamer "sigue incluso hoy cultivando la ciencia noble en continuación de su esteticismo anterior" (Leaman, 1993, 40-41) ${ }^{17}$. El comentario era conocido por Orozco, que decidió simplemente referenciar la página del libro de Leaman en su artículo sin mencionar nada más (2004a, 70, n. 22). No parece ser una felicitación de bienvenida para un fiel camarada. El cultivo de la "ciencia noble" y su "esteticismo anterior" hacen de Gadamer un docente políticamente neutral y su Plato und die Dichter una pieza ideológicamente inútil y poco en sintonía con las expectativas de la Facultad de Filosofía de la Marburgo nacionalsocialista.

\section{Richard Wolin: “...das andere Mal als Farce”.}

Untruth and Method: Nazism and the Complicities of Hans-Georg Gadamer [Falsedad y método: nazismo y complicidades de Hans-Georg Gadamer]

16 "La noticia de la invasión de Normandía me fue murmurada al oído por la hija de Goerdeler delante del edificio de la biblioteca. Luego se produjo el fallido atentado del 20 de julio, al que siguió una nueva ola de terror que nos quitó el aliento a todos" $(1996,144)$. Una vez desatada la ola de procesos, es posible que Gadamer haya tenido motivos para temer ser identificado como parte del grupo de complotistas.

17 Ibíd. 
El debate sobre Plato und die Dichtery su inscripción en el contexto de Alemania Nacional-Socialista: una discusión con lecturas de la teoría política

de Richard Wolin no tiene ni siquiera el mérito de la originalidad. El artículo, aparecido en 2000 en The New Republic, luego ligeramente ampliado y publicado como capítulo de su libro The Seduction of Unreason: The Intellectual Romance with Fascism from Nietzsche to Postmodernism (2004, 89-128) [La seducción de la insensatez: el romance intelectual con el fascismo de Nietzsche al Posmodernismo] ${ }^{18}$, es prácticamente una duplicación del trabajo de Orozco, con algunos agregados insignificantes y parroquiales, como, por ejemplo, el ataque gratuito a Richard Rorty (luego eliminado en la versión de 2004). Como vislumbró con claridad Donatella Di Cesare, es evidente que tanto Wolin como Orozco, más allá de Gadamer, "tenían en su mira a la hermenéutica" (2007, 26), pero en el caso particular de Wolin "por la ausencia de contenidos, — continúa la autora - este ensayo termina desafortunadamente por ser una denigración de Gadamer" $(26)^{19}$. Basta recordar el descomedido nombre que el texto recibió en su libro de 2004: "Fascism and Hermeneutics" [Fascismo y hermenéutica].

En el año 2001 la revista Internationale Zeitschrift für Philosophie, en un volumen titulado Hermeneutik und Politik in Deutschland vor und nach 1933 [Hermenéutica y política en Alemania antes y después de 1933] recogió varias intervenciones que tuvieron como objetivo apoyar o responder a los textos de Orozco y, sobre todo, a Wolin. Entre sus autores se encuentran Georgia Warnke, Robert Sullivan y Gabriel Motzkin, siendo la intervención de este último quizás la más destacada. Al año siguiente se publicó un artículo de Richard E. Palmer (2002b) que definitivamente mostró con claridad la numerosa serie de inconsistencias, errores y omisiones de Wolin, algunas de las cuales provenían de su reproducción del texto de Orozco. En 2004 un texto de Catherine Zuckert corrigió muchas de las inexactitudes de la lectura de la autora mexicana ${ }^{20}$.

En su artículo, Motzkin señaló que si hay algo que le escapó a la comprensión de Wolin fue que Gadamer siempre fue irónico consigo mismo en sus memorias, en su forma de lidiar con el pasado (2001, 81). Pero no sólo en ese sentido la ironía está presente en sus textos. Di Cesare $(2007,26)$ ha notado la importancia de seguir otra interesante pregunta que pone Motzkin a la obra de

18 El término inglés Unreason es utilizado en el título con una ambigüedad tal que permite ser traducido por "insensatez", aunque también esté remitiendo a "irracionalidad". Sin embargo, el tono polémico busca sólo cargar las tintas sobre lo carente de razón en el sentido de la salud mental, y no a cuestionamientos filosóficos de la Razón que, de ningún modo, pueden ser reducidos a una apología de la más llana locura.

19 La traducción me pertenece.

20 En ese mismo texto Zuckert inició un debate con Geoffrey Waite que tuvo también a la hermenéutica filosófica y su relación con la política en el centro. Sobre las consideraciones críticas de este último en torno a las supuestas repercusiones políticas de un nietszcheanismo subyacente y encubierto de Gadamer cfr. Waite (2004, 169-211, 256-306). 
Gadamer: ¿cuál es el juego posible entre autoridad e ironía, entre tradición y subversión? (Motzkin, 2001, 81).

No puedo ofrecer aquí un principio de respuesta a esta interesante pregunta. Pero sí, en cambio, me gustaría dejar planteada una observación. Las acusaciones de Orozco y Sullivan tienen un eje común: Gadamer habría contribuido con o sido cómplice del nacionalsocialismo y lo hizo, justamente, gracias a su poco compromiso con el nacionalsocialismo. La misteriosa ambigüedad de sus textos reflejaría una estrategia aviesa y la ausencia de críticas dirigidas a la dictadura nazi en los dos textos que publicó en esos años desmentirían cualquier posibilidad de desacuerdo con los acontecimientos en curso. El double bind del argumento podría resumirse del siguiente modo: Gadamer es culpable de no haber sido un héroe o un mártir de la resistencia antifascista - aunque Orozco se empeñe en negar esta pretensión (2004b, 245)-, pero también es culpable de no haber sido un nazi comprometido con la causa del NSDAP. Orozco incluso se permite citar la desafortunada y trágicamente inexacta frase de la socióloga francesa Isabelle Kalinowski: "el odio al Estado de derecho de Weimar desplegó, sin duda, en los comentarios de Gadamer a Platón una forma más profunda de efectividad que el compromiso directo de Heidegger, quien paradójicamente demuestra una mayor ingenuidad política" (Orozco, 2004a, 86-87; Kalinowski, $1997,14)^{21}$. El irónico romántico, el descomprometido Gadamer parece perfectamente descrito en los términos de Orozco y Wolin en las siguientes líneas:

El romántico se sustrae irónicamente a la objetividad opresiva y se guarda de comprometerse a cualquier cosa; en la ironía se encuentra la reserva de todas las posibilidades infinitas. Así se preserva su genial libertad interior, la cual consiste en no renunciar a ninguna posibilidad $(2000,134)$.

Estas inconfudibles palabras pertenecen a Carl Schmitt. ¿Debería hablarse entonces de un secreto (e irónico) schmittianismo en el subtexto de los trabajos de Orozco y Wolin? Seguramente sería necio hacer algo así. Pero eso no implica dejar de subrayar cuánto sus mecanismos de acusación se nutren de argumentaciones que seguramente a estos mismos autores no les enorgullecería mu-

21 Aunque muchos de los hechos recientemente públicos (como la participación de Heidegger en la Kommission für die Rechtsphilosophie hasta julio de 1942) y los textos en actual proceso de publicación aún no se conocían en 1995, existían ya elementos suficientes para que las comparaciones con Gadamer fueran inaceptables. 
cho vindicar. El reproche a Gadamer, la imputación de haberse negado a tomar una decisión clara y manifiesta en términos políticos, su supuesta ambigüedad ocasionalista, resulta (volver a) tomar el tono, por parte de los acusadores, de un culto por la decisividad, cuyo contenido no parece ser más sólido que la occasio de sus agendas. En todo caso, me permito tan sólo recordar que lo que revive aquí es una contradicción que marcó con lucidez Karl Löwith en 1935 sobre el decisionismo schmittiano (2006, 43-89).

[...] siempre creí que fui un liberal. Es verdad: yo no hablaba de esas cosas durante el Tercer Reich. No habia necesidad, ni para mi ni para mis amigos, de reportarle directamente al verdugo que éramos parte de la oposición. Así fue que comencé a escribir sobre filosofía griega, antes de 1933, de un modo eminentemente politico, por ejemplo, sobre los sofistas. [...] Tuve que abstenerme de todo esto, asi que solo publiqué Platón y los poetas Hans-Georg Gadamer (1992, 148).

\section{Conclusiones}

Gadamer demostró con suficiencia la importancia de no reducir una obra a ser una mera Roman à clef (novela en clave, narración alusiva), en ocasión de su crítica al trabajo de Carl Schmitt sobre William Shakespeare, Hamlet oder Hekuba: der Einbruch der Zeit in das Spiel [1956] [Hamlet o Hécuba. La irrupción del tiempo en el drama]. En aquel pasaje desatendido de los anexos a Wahrheit und Methode [Verdad y método], afirmó que

La ocasionalidad debe mostrarse como un momento de sentido dentro de la pretensión de sentido de una obra, no como el rastro de las ocasionalidades que se oculta tras la obra y que la interpretación debe poner al descubierto. Si lo último fuese cierto, esto significaría que sólo restaurando la situación original podría uno ponerse en condiciones de comprender el sentido del conjunto. Por el contrario, si la ocasionalidad es un momento de sentido en la pretensión de la obra misma, entonces 
el camino de la comprensión del contenido de sentido de la obra representa a la inversa, para el historiador, una posibilidad de conocer algo sobre la situación original a la que habla la obra (Gadamer: 2017, 590).

La advertencia gadameriana difícilmente pueda ser indiferente, pues prepara para nosotros, sus lectores, la pregunta ¿a qué situación habla Plato und die Dichter?

Cuando Gadamer afirmó que la verdadera irrupción es la de la obra en el tiempo - en su ejecución, con su ambigüedad-y no, en cambio, su permanecer cerrada sobre sí, se refería a que "la obra misma puede responder a cada ocasión en virtud de su capacidad de hablar" $(2017,592)$. Cualquier operación en otro sentido presupone una falsa oposición entre juego y tiempo y caricaturiza a la obra de arte como perteneciente a "un mundo cerrado de experiencias estéticas", ignorando que ésta ya se encuentra desde un inicio en el tiempo y desde allí se realiza siempre como irrupción $(2017,591)$. Entiendo que es importante intentar seguir este camino metodológico y evitar todo "falso historicismo" que enmudezca o desatienda la lingüisticidad del texto o que coloque a la política de un lado o del otro de esa artificiosa antítesis entre arte e historia.

¿En qué sentido podría decirse que el texto excedería su contexto, como afirmó Fred Dallmayr en un artículo (1990)? Justamente porque "en el juego mismo no hay oposición alguna entre tiempo y drama [...] dado que, al contrario, el drama es el que implica al tiempo en su juego" (GW 2, 379; énfasis

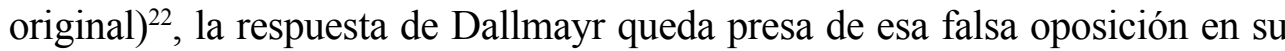
interpretación del texto y hace reingresar por una puerta lateral ese "exceso" en el que consistiría su marco temporal. Este problema se hace patente en el texto al resaltar Dallmayr que el interés de Gadamer por Platón lejos de estar motivado por intereses estrictamente filológicos, en cambio, se sustentaba en un precedente y subyacente diagnóstico de la crisis de la cultura alemana en el que esta resultó equiparada a la crisis del modo de vida de Atenas, en los años que van de Sócrates a Aristóteles (Dallmayr, 1990, 94; GW 5, 230).

22 La versión de Agud Aparicio y de Agapito (2017) traduce el alemán "Für das Spiel selbst ist kein Gegensatz von Zeit und Spiel, [...] gegeben, Vielmehr bezieht das Spiel die Zeit in sein Spiel mit ein" (GW 2, 379) de un modo poco comprensible por: "En la obra misma no se da ninguna oposición entre tiempo y desarrollo [...]. Al contrario, es más bien el juego el que implica el tiempo en su propio juego" $(2017,591)$. Este texto apareció en su idioma original en el segundo tomo de Wahrheit und Methode, mientras que en castellano fue añadido al primero. Como señaló con agudeza Sullivan, la importancia del concepto de juego aparece ya en la tesis de habilitación de Gadamer y, aún con más intensidad, en Plato und die Dichter (Sullivan, 1989, 152). 

lecturas de la teoría política

La situación crítica de la Alemania de Weimar y su paralelo con la crisis ateniense no constituyó una comparación antojadiza por parte de Gadamer sino un poderoso lugar común, un mito de la intelectualidad alemana, instalado por Johann Joachim Winckelmann y explotado por el romanticismo, cuyas derivas han sido variadas y con repercusiones políticas muy diversas. La primera en ver críticamente este paralelo fue la profesora de alemán de la Universidad de Cambridge Eliza Marian Butler, que en 1935 publicó un libro cuyo título fue The Tyranny of Greece over Germany: A Study of the Influence Exercised by Greek Art and Poetry over the Great German Writers of the Eighteenth, Nineteenth and Twentieth Centuries [La tiranía de Grecia sobre Alemania: un estudio de la influencia ejercida por el arte y la poesía griegos sobre los grandes escritores alemanes de los siglos dieciocho, diecinueve y veinte], obra prohibida en la Alemania nacionalsocialista que, según es posible saber por documentación inédita que he consultado en el Deutsches Literaturarchiv Marbach am Neckar (DLA), Gadamer conoció en los años inmediatamente posteriores a su publicación. Más contemporáneamente, Philippe Lacoue-Labarthe y Jean-Luc Nancy han visto en aquel lugar común el síntoma catastrófico de una necesidad de los alemanes de asegurarse una identidad, fundamentalmente apelando al arte como instrumento mimético de identificación por excelencia para una nación privada de ser "el sujeto de su propio devenir" (2011, 31). La particularidad esquizofrénica de esta identificación entre Alemania y "Grecia” habría que buscarla en la lógica del double bind que la guió: "la apropiación del medio de identificación, simultáneamente, deb[ía] y no deb[ía] pasar por la imitación de los antiguos, es decir, antes que nada de los griegos" (2011, 31-32).

Lo que sabemos con certeza de la letra de Gadamer, es que la precaución [vorsichtshalber] política —o, más bien, el instinto de conservación— lo acompañó al menos en el momento en el que decidió interrumpir un estudio de más largo aliento sobre la "teoría sofística y platónica del Estado" en el que se encontraba entonces trabajando, del cual Plato und die Dichter y Platos Staat der Erziehung [1942] constituyeron "aspectos parciales" (Gadamer: 1998, 384). La oposición de Gadamer frente al poder constituido es ciertamente ostensible desde el epígrafe del texto, tal como él reconoció en más de una oportunidad (1998, 384; 1997, 256).

Dicho esto, cuánto la filosofía podía ser un modo de acción subsidiario, una posibilidad de manifestar oposición de la que se sirvió Gadamer en virtud de que otros canales habían sido cerrados por el nazismo, es algo que no podemos inferir.

En su Selbstdarstellung [Autopresentación] [1975], incluida en Wahrheit und 

lecturas de la teoría política

Methode 2 [1986], Gadamer había afirmado que Plato und die Dichter "[...] expone la interpretación, que aún hoy considero la única verdadera, según la cual el Estado ideal de Platón representa una utopía expresa que tiene que ver más con Swift que con la ciencia política" $(1998,384)$. No obstante, con esta afirmación no parece que Gadamer busque trivializar el valor propio del tópico del texto. Por el contrario, la misma referencia a Jonathan Swift, el reenvío en nota al pie a su texto posterior Platos Denken in Utopien [Platón y el pensar en utopías] [1983], así como la aclaración sobre el gesto político que significó para el autor la inclusión posterior del epígrafe de Johann Goethe, son todos elementos que refuerzan el carácter polémico y político del escrito. Y, aunque Gadamer buscará aclarar en ocasión de la respuesta a un texto de Robert Sullivan que caracteriza a Plato und die Dichter como "una reflexión sobre la condición política moderna, directamente adversativa con [respecto a] las nuevas condiciones de la Alemania nazi" $(1997,239)^{23}$, que la conferencia en cuestión no fue pensada ni dirigida hacia al nazismo como fenómeno ${ }^{24}$ - lo cual confirma el dato que aporta Grondin sobre que la primera versión fue escrita antes del 30 de enero de 1933 (2000, 204) - , el autor no dejará de afirmar que sus investigaciones tenían su sentido propio en y desde la democracia liberal de Weimar, en el marco de una preocupación más general sobre los acontecimientos políticos, y sobre el arte y la poesía como generadores de nuevas experiencias, preocupación intelectual en la que la figura de Sócrates se encontraba en el centro, "fundamentalmente en el esfuerzo de dejar cuestiones abiertas" (Gadamer, 1997, 257). La inclusión posterior del epígrafe en la versión impresa desempeñaría el rol de una humilde muestra de resistencia contra "el espíritu de igualación", frente al requisito de alineamiento [Gleichschaltung] con el partido $(1996,64)^{25}$.

¿Qué postura podemos adoptar como miembros de una comunidad política, académica, ante un pensamiento, "una acción, un discurso, un comportamiento" al que no le permitimos atravesar con nosotros lo que Jacques Derrida llamó, aunque en un contexto muy distinto, su "aterradora prueba de indecidibilidad"26

23 La traducción me pertenece.

24 Luego, refiriéndose a las implicancias políticas que Sullivan encontró en Plato und die Dichter: "Para mí siempre fue claro que podrían haber tenido alguna validez sólo como un ejercicio [realizado] en una democracia liberal y no dirigido al «Reich de los mil años»" (Gadamer, 1997, 257).

25 El término Gleichschaltung en este contexto no significa mera "normalización" como traduce Fernández de Marur Duque, sino que indica un plan sistemático concreto de nazificación de la sociedad y sus instituciones desarrollado en esos años, que en la literatura historiográfica se lo traduce habitualmente por "coordinación".

26 La traducción me pertenece. 

lecturas de la teoría política

(Derrida, Gadamer, Lacoue-Labarthe, 2014, 126), ese conflictivo camino a lo largo del cual uno no puede desembarazarse tanto de la palabra más justa cuanto de sus silencios más definidos de un autor? Gadamer ha sido muy claro con respecto a los problemas metodológicos que acarrea la investigación de las huellas políticas coyunturales en la obra de un autor, usando el caso de William Shakespeare paradigmáticamente: si un poeta, como el bardo de Avon, hubiera de hecho pertenecido secretamente a un partido, habría debido ocultarlo ya que en su auditorio se encontraría también el partido opuesto. Además, opera de fondo una reducción de las posibilidades políticas de una obra artística a su valor partidario y a su correspondiente funcionalidad circunstancial. Es el juego de la obra el que irrumpe ocasionalmente en el tiempo y "ambiguo como es, el juego sólo puede desarrollar sus imprevisibles efectos en su ejecución. Por su esencia no es apropiado para convertirse en instrumento de objetivos enmascarados que habría que poder adivinar para entenderlo". Por todo ello es que "como juego le es inherente una ambigüedad irresoluble" (Gadamer, 2017, 591).

Sin esta ambigüedad no hay interpretación posible, ni filosófico-política, ni de ningún otro tipo. No hay novedad, sólo un permanecer en la lógica clasificatoria de una suerte de botánica histórico-política: "La productiva plurivocidad en que consiste la esencia de la obra de arte no es más que otra manera de expresar la determinación esencial del juego, que es convertirse cada vez en un acontecimiento nuevo" $(2017,592)$.

Sin embargo, esto último no implica un regreso reaccionario al servicio de la neutralización social que realiza el consumo estético como diría Wolfgang Fietkau en 1978 en su carta a Jacob Taubes ${ }^{27}$ (Taubes, Schmitt, 2018, 136). Esta caracterización, que Taubes compartiría y haría llegar al propio Schmitt, por la cual Gadamer restituiría a la consciencia estética su primado es simplemente insostenible para quien conoce su obra: es una posición que Gadamer de hecho combatió clara y tempranamente en su Plato und die Dichter (GW 5, 206). En todo caso, lo que se pone en juego para Gadamer en el acontecimiento histórico de la obra, es una distinta concepción de la relación con la contingencia. Taubes, en una carta a Schmitt, en la que criticó la interpretación de Gadamer del Hamlet oder Hekuba, puso en el centro común de sus intereses filosóficos con el jurista de Plettenberg a la esencia del drama "en sentido bíblico o cristiano", es decir, aquello "temporalmente determinado, [...] irreversible [...]" (Taubes, Schmitt, 2018, 79). Gadamer, en el esquema que planteaba dicha carta, quedaba del lado del «tiempo pagano» con su noción «trágica» de Spiel, pero no porque

27 Carta del 30 de noviembre de 1978 (Taubes, Schmitt, 2018, 136). 

lecturas de la teoría política

su filosofía se dirigiera hacia lo que no está "temporalmente determinado" sino porque la hermenéutica jamás podría renunciar a la fecunda ambigüedad originaria de la fábula, a la raíz mitológica y dialéctica de toda obra.

Gadamer no se encontraba interesado en la figura de Sócrates porque le permitiera obtener un conocimiento acabado de la realidad o porque demostraba ser una figura heroica para un tiempo anómico, pasado o presente, sino porque la hermenéutica filosófica trabaja "fundamentalmente en el esfuerzo de dejar cuestiones abiertas" (Gadamer, 1997, 257). Pues, como se puede leer en su crítica a la lectura schmittiana de Shakespeare, "un drama en el que absolutamente todo estuviese motivado rechinaría como una máquina", en la medida en que “cuantas más cosas queden abiertas, más libre será la comprensión, esto es, la proyección de lo que se muestra en la obra al propio mundo, y por supuesto también al propio mundo de experiencias políticas" $(2017,592)$.

Para Gadamer, la cita de Goethe significó, al menos, dos cosas — deseo resaltar, entre muchas otras que aún podemos reconocer no por fuera, sino dentro y entre las relaciones de sentido del texto- - un modo, aunque sutil, de expresar su disidencia con la hegemonía nacionalsocialista y "un modo de subrayar la propia identidad", de ser él mismo, diferenciándose — a pesar y dentro de su inmadurez política — de los cómplices. A su modo se planteó, como lo hizo Platón, "la cuestión de cómo debe practicar la filosofía una ciudad que no quiera perecer" (Rep. 497d) ${ }^{28}$ es decir, no de cómo hacer imperecedera la filosofía por encima de la pólis, por fuera de ella; tampoco de cómo ordenar la pólis al precio de sacrificar hasta el último resguardo reflexivo, ni de cómo dirigir espiritualmente a la política.

Plato und die Dichter no puede ser entendido como un texto apolítico, ni como una alocución apologética del nazismo ni tampoco como una crítica radical del régimen. La politicidad del texto gadameriano no pierde potencia propia por no estar consagrado enteramente a discutir el nacionalsocialismo. El hecho de que Gadamer haya afirmado que la conferencia Plato und die Dichter no fue pensada ni dirigida hacia al nazismo como fenómeno político, sino que fue concebida en y desde la democracia liberal de Weimar, en el marco de una preocupación más general sobre los acontecimientos políticos como generadores de nuevas experiencias, podría permitir, en todo caso, una lectura atenta a su tematización de la democracia. En ese sentido, en cuanto sus raíces se encuentran en el terreno propio de la crisis de la República de Weimar, su lectura abriría eventualmente un nuevo camino para entender el deslizamiento cultural y político desde el régimen que se inició en noviembre de 1918 hacia al totalitarismo,

28 Traducción de Pabón y Fernández Galiano. 
una nueva posibilidad de interrogar los posibles desplazamientos simbólicos desde el orden democrático hacia el autoritarismo.

Para finalizar, vale recuperar dos sentencias aparecidas en las primeras dos publicaciones de Gadamer, a sus veinticuatro años, que hoy se pueden conjugar sin violentar nuestro lugar ni el del autor. Si "lo esencial de la posición filosófica" descansa en "[...] soportar el problema en su indecidibilidad y su patente falta de certeza" (1924a, 57), eso no nos exime de reconocer que "no hay modo de alcanzar la cosa que no esté determinado en manera decisiva por la peculiaridad de la propia posición" (1924b, 341).

Al estudiar Plato und die Dichter es factible recorrer un orden fragmentario, cuyas piezas reunidas con dificultad nos devuelven preguntas como imágenes que despiertan dentro nuestro: posibilidades a las que el lector no le es posible renunciar. La importancia histórica de Plato und die Dichter seguramente no esté en lo que nos da a ver de su contexto, sino en cómo ha logrado implicarnos a sus lectores. Está en su irrupción en el tiempo.

Autor (2017).

Autor (en prensa).

Cherniss, H. (1936). "H.-G. Gadamer. Plato und die Dichter. Frankfurt, Klostermann Verlag, 1934”. En The American Journal of Philology, Vol. 57, No. 2, The Johns Hopkins University Press, 229-230.

Dallmayr, F. (1990). "Hermeneutics as Justice". En Festivals of Interpretation: Essays on Hans-Georg Gadamer's Work, Kathleen Wright (ed.), Albany, NY: State University of New York Press, 90-110.

Derrida, J., Gadamer, H.-G., Lacoue-Labarthe, P.,
(2014). Conférence de Heidelberg. Portée philosophique et politique de sa pensée: rencontre-débat de Heidelberg, 5 et 6 février 1988, París: Lignes.

Di Cesare, D. (2007). Gadamer, Bologna: Il Mulino. Fritz, K., v. (1936). "Hans Georg Gadamer: Plato und die Dichter. Frankfurt a. M.: Klostermann 1934”. En Gnomon, 12. Bd., H. 5 (May), 251-255.

Gadamer, H.-G. (1924a). "Zur Systemidee in der Philosophie". En Festschrift für Paul Natorp zum 70. Geburtstage von Schülern und Freunden gewidmet, Berlin: De Gruyter, 55-75. 
. (1924b). "Metaphysik der Erkenntnis. Zu dem gleichnamigen Buch von Nicolai Hartmann". En Logos XII, 1923/4: 340-360.

(1992). Gadamer on Education, Poetry, and History: Applied Hermeneutics, Dieter Misgeld, Graeme Nicholson (eds.), trads. al inglés Lawrence Schmidt, Monica Reuss, Albany: State University of New York.

(1996). Mis años de aprendizaje, trad. de Rafael Fernández de Maruri Duque, Barcelona: Herder.

(1997). "Reply to Robert R. Sullivan". En Lewis Edwin Hahn (ed.), The Philosophy of Hans-Georg Gadamer, Library of Living Philosophers, v. 24. Open Court, 256-258.

(1998). Verdad y método II, trad. Manuel

Olasagasti, Salamanca: Sígueme.

. (2002). Die Lektion des Jahrhunderts: ein Interview von Riccardo Dottori, Vol. Wissenschaftliche Paperbacks, Münster: LIT.

(2017). Verdad y Método I. Fundamentos de una hermenéutica filosófica. Trads. Ana Agud de Aparicio y Rafael de Agapito, Salamanca: Sígueme.

. GW Hans-Georg Gadamer, Gesammelte Werke, Tübingen: Mohr Siebeck, 1985-1995.

.(GW 1). Hermeneutik 1 (Wahrheit und Methode. Grundzüge einer philosophischen Hermeneutik), 1986.

(GW 2). Hermeneutik 2 (Wahrheit und Methode [II]: Ergänzungen. Register), 1986.

(GW 5). Griechische philosophie I, 1985.

Hildebrandt, K. (1933a). Platon. Der Kampf des Geistes um die Macht, Berlin: Bondi.

.(1933b). Platon. Der Staat, Stuttgart:

Kröner.
.(1935). Platon. Der Staat, Leipzig: Kröner.

Kalinowski, I. (1997). "Les ambiguïtés de Gadamer". En Liber. Revue internationale des livres, 30.

Lacoue-Labarthe, P., Nancy, J.-L. (2011). El mito nazi, trad. de Juan Carlos Moreno Romo, Barcelona: Anthropos.

Leaman, G. (1993). Heidegger im Kontext Gesamtüberblick zum NS-Engagement der Universitätsphilosophen, Hamburg: Argument.

Löwith, K. (2006). "El decisionismo ocasional de Carl Schmitt". En Heidegger, pensador de un tiempo indigente, Buenos Aires: Fondo de Cultura Económica.

Motzkin, G. (2001). "Comment on Richard Wolin's >Untruth and Method `". En Internationale Zeitschrift für Philosophie, Schwerpunktthema: "Hermeneutik und Politik in Deutschland vor und nach 1933", Bd. 9, 78-85.

Orozco, T. (1995a). Platonische Gewalt. Gadamer's politische Hermeneutik der NS-Zeit, Hamburg: Argument.

.(1995b). "Die Kunst der Anspielung. Hans-Georg Gadamer im NS”. En Argument, 209, 311-324.

.(2004a). "El arte de la insinuación. Las intervenciones filosóficas de Hans-Georg Gadamer en el Nacionalsocialismo". En Laguna: Revista de Filosofía, Tenerife: Universidad de la Laguna, no. $14,65-88$.

Orozco, T. (2004b). "The Protection of the Philosophical Form: A Response to Zuckert”. En Gadamer's Repercussions: Reconsidering Philosophical Hermeneutics, Berkeley: University of California Press, 244-255.

Pabón, J. M. et al (1981). Platón. La República, Madrid: Centro de Estudios Constitucionales. 
Palmer, R. (2002a). "How Gadamer Changed My Life. A Tribute". En Symposium, Vol. 6, No. 2, Fall, 219-230.

Palmer, R. (2002b). "A Response to Richard Wolin on Gadamer and the Nazis". En International Journal of Philosophical Studies, 10, 467-482.

Stanford, W. S. (1937). "Plato und die Dichter by Hans-Georg Gadamer. Vittorio Klosterman, Frankfurt”. En Hermathena, Vol. 25, No. 50, 233-234.

Sullivan, R. (1989). The Early Thinking of Hans-Georg Gadamer, University Park: Pennsylvania State University Press.

Sullivan, R. (1997). “Gadamer's Early and Distinctively Political Hermeneutics". En Lewis Edwin Hahn (ed.), The Philosophy of Hans-Georg Gadamer, Library of Living Philosophers, v. 24. Open Court, 237-255.

Tate, J. (1928). “«Imitation» in Plato's Republic”. En Classical Quarterly 22, 16-23.

Tate, J. (1932). "Plato and «Imitation»". En Classical Quarterly 26, 3-4, 161-169.

Tate, J. (1936). "Gadamer H. G.: Plato und die Dichter. Pp. 36. Frankfurt am Main: Klostermann, 1934”. En The Classical Review, 50(4), 147-147.

Taubes, J., Carl Schmitt (2018). Ai lati opposti delle barricate: Corrispondenza e scritti 1948-1987. Herbert Kopp-Oberstebrink et al. (eds.). Trad. de Giovanni Gurisatti. Milano: Adelphi.

Verdenius, W. J. (1944). "Platon et la poesie". En Mnemosyne, Third Series, Vol. 12, Fasc. 2, 118-150.

Waite, G. (2004). "Radio Nietzsche, or, How to Fall Short of Philosophy”. En Gadamer's Repercussions: Reconsidering Philosophical Hermeneutics, Berkeley: University of California Press, 169-211.

Westerburg, n/n (1934). "Bericht aus Marburg (Lahn)”. En Das humanistische Gymnasium, no. 45,
100-100.

Wolin, R. (2000). "Untruth and Method: Nazism and the Complicities of Hans-Georg Gadamer". En The New Republic, 15 de mayo, 36-45.

Wolin, R. (2004). The Seduction of Unreason, The Intellectual Romance with Fascism: From Nietzsche to Postmodernism, Princeton: Princeton University Press. 